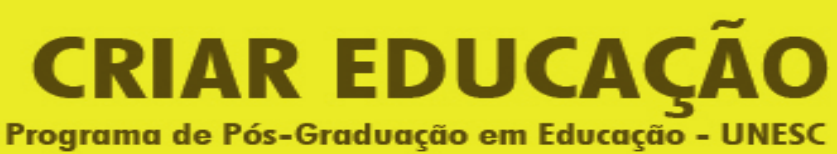

Revista do Programa de Pós-Graduação em Educação - UNESC

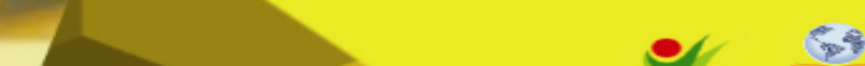

unesc

PPG

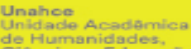

ediunesc

\title{
REFLEXÕES SOBRE A FORMAÇÃO DOCENTE PARA ATUAÇÃO NO BERÇÁRIO
}

\section{REFLEXIONES SOBRE LA FORMACIÓN DE PROFESORES PARA ACTUAR EN VIVERO}

DIOGO, Maria Fernanda ${ }^{1}$

\begin{abstract}
RESUMO
Este artigo analisa a mediação em relação ao brincar e à aquisição da linguagem dos bebês no espaço da creche, discutindo a relevância de os/as docentes terem acesso a processos formativos de qualidade, que preparem professores/as reflexivos/as e críticos/as em relação ao ensino e às condições sociais nas quais este se processa. As pesquisas aqui analisadas foram efetivadas por meio de estudos de campo, realizados em instituições públicas de Educação Infantil. A análise das informações colhidas enfatiza a necessidade de os/as docentes adotarem práticas educativas que superem a dicotomia entre o cuidar e o educar, considerando toda e qualquer interação plena em potencialidades de aprendizados, pois no berçário há inúmeras alternativas de trabalho nas quais os bebês podem construir conhecimentos de forma ativa, utilizando múltiplas linguagens.
\end{abstract}

Palavras-chave: Formação Docente; Berçário; Brincar; Linguagem.

\section{RESUMEN}

Este artículo analiza La mediación en relación a jugar y La adquisición Del lenguaje de los bebés dentro Del vivero, discutiendo La importancia de los maestros tendrán acceso a los procesos de La capacitación de calidad, para preparar profesores reflexivos y críticos enrelación con La enseñanza y las condiciones socialesen que las se efectúe. Las investigaciones aquí revisadas se hicieron a través de estudios de campo en instituciones públicas de Educación Infantil. El análisis de lãs informaciones recogidas enfatizan La necesidad de los profesores adoptar prácticas educativas que superen La dicotomía entre La atención y La educación, teniendo encuenta toda e cualquier interacción llena en el potencial de aprendizaje, porque en El vivero hay numerosas alternativas de trabajo en el que los bebés pueden construir activamente El conocimiento, utilizando múltiples linguajes.

Palabras Clave: Formación Docente; Vivero; Jugar; El Lenguaje.

\footnotetext{
${ }^{1}$ Faculdade Municipal de Palhoça/SC. Endereço eletrônico: mafediogo@gmail.com.
} 


\section{INTRODUÇÃO}

Como docente na Licenciatura em Pedagogia, tenho percebido crescente interesse dos/as graduando/as realizarem pesquisas sobre o berçário, o que pode denotar que os/as futuros/as pedagogos/as estão mais cientes da importância do trabalho pedagógico realizado com os bebês. Este trabalho entrelaçou as análises efetuadas pelas acadêmicas Adriele de Souza Taborda (2015)e Nikely Flores Limas (2015) em suas monografias, por mim orientadas. A primeira se debruçou sobre a influência da brincadeira no processo de ensino-aprendizagem dos bebês no espaço da creche, a segunda analisou a mediação das professoras no desenvolvimento da linguagem dos bebês. $O$ objetivo deste artigo é discutir a relevância dos processos formativos aprofundarem conhecimentos quanto ao desenvolvimento físico, cognitivo, afetivo e sócio histórico dos bebês, instrumentalizando os/as futuro/as docentes nas práticas pedagógicas específicas para o berçário e refletindo sobre a indissociabilidade entre o cuidar e o educar.

A base teórica que sustentou as análises propostas em ambas as monografias foi a perspectiva Sócio Cultural, apresentada por Vygotski e seus colaboradores. Esta teoria considera que o sujeito e a sociedade estabelecem uma relação dialética, constituindo-se mutuamente. Nos processos de aprendizagem, os bebês internalizam a cultura por intermédio das suas relações sociais. Os adultos se comunicam gestual e verbalmente com eles, significam seus gestos e sons e influenciam na forma como veem e interpretam o mundo, ou seja, influenciam na formação das suas Funções Psicológicas Superiores. Assim, pode-se afirmar que a cultura redimensiona o biológico (VYGOTSKI, 1994).

Segundo a teoria Sócio Cultural, a boa educação é aquela que se antecipa ao desenvolvimento. "É como se o processo de desenvolvimento progredisse mais lentamente que o aprendizado; este desperta processos de desenvolvimento que, aos poucos, vão tornar-se parte das Funções Psicológicas já consolidadas no indivíduo" (OLIVEIRA, 1993, p. 60). A função da escola, nesta perspectiva, é formar uma Zona de Desenvolvimento Proximal, fomentando o desenvolvimento potencial de seus alunos(VYGOTSKI, 1994).

\section{MÉTODO}

Criar Educação, Criciúma, v. 6, no1, julho/novembro 2016.- PPGE - UNESC 
As duas monografias foram realizadas em instituições públicas de Educação Infantil, localizadas no município de Palhoça/SC. Em ambas, o método foi qualitativo, buscando compreender os fenômenos pela sua descrição e interpretação.

Taborda (2015) realizou observações sistemáticas em uma turma de crianças entre um e dois anos de idade, objetivando descrever e analisar suas brincadeiras e como estas eram mediadas pelas professoras. Foi realizado o registro fotográfico de algumas brincadeiras, com a autorização formal das professoras e dos pais por meio da assinatura do Termo de Consentimento Livre e Esclarecido (TCLE). Também foram aplicados questionários a seis professoras atuantes em turmas do GTI, objetivando reconhecer a significação que estas atribuíam ao brincar nesta faixa etária.

Limas (2015) também realizou observações sistemáticas em uma turma de crianças entre um e três anos de idade, com o objetivo de descrever as diferentes linguagens usadas na interação entre as crianças e delas com as professoras, reconhecendo as possibilidades de mediação das diferentes formas de expressão de cada bebê. Também foram realizadas entrevistas semiestruturadas com as duas professoras da turma, objetivando aprofundar como estas significavam e mediavam o desenvolvimento da linguagem dos bebês. As observações e as entrevistas foram autorizadas por meio da assinatura do TCLE.

$\mathrm{Em}$ ambas as pesquisas, as informações coletadas foram analisadas utilizando categorias de análise. Para fins deste artigo, tomando como base e avançando qualitativamente na investigação efetuada nas duas monografias, foram entretecidas análises, dentro do referencial da teoria Sócio Cultural, sobre a importância da formação docente específica para o trabalho no berçário.

\section{A FORMAÇÃO DE PROFESSORES/AS PARA O TRABALHO NO BERÇÁRIO}

A Educação Infantil foi, por muitos anos, permeada por um viés assistencialista, fazendo com que este nível de ensino ainda sofra um problema de identidade que não permeia os outros níveis. Seu ambiente representa a primeira etapa da Educação Básica e precisa constituir-se em um espaço no qual a criança aprenda 
novos conhecimentos e, também, receba cuidados básicos, tais como higiene, cuidados com sua a saúde e nutrição. Assim, ao exercer ações de cuidado, tanto físicos como afetivo-emocionais, o/a professor/a também precisa estar atento/aao desenvolvimento da criança e à sua aprendizagem. Os documentos oficiais reforçam esta visão de indissociabilidade entre o cuidar e o educar, com destaque para as Diretrizes Curriculares Nacionais para a Educação Infantil (BRASIL, 2010) e para o Referencial Curricular Nacional para a Educação Infantil(RCNEI), aqui citado: "contemplar o cuidado na esfera da Instituição de Educação Infantil significa compreendê-lo como parte integrante da educação" (BRASIL, 1998, p. 24).

As premissas da Educação Infantil estabelecidas nestes documentos consideram cada criança sujeito histórico e social, ser singular e único, capaz de construir conhecimentos e sua identidade pessoal e coletiva pela interação com o meio e com as outras pessoas (BRASIL, 1998; 2010). Assim, o/as docentes precisam saber respeitar os bebês em sua singularidade, auxiliá-losna elaboração de seus pensamentos e a se transformarem em agentes atuantes na sociedade. Para isso, faz-se necessário que, em seus processos de formação, ele/as tenham refletido sobre práticas educativas de qualidade para o berçário.

A formação profissional docente está atrelada aos saberes desenvolvidos pelos/as professores/as nos seus processos de formação inicial e continuada e, também, no cotidiano de suas atividades. Segundo Therrien (1998, p. 59), o saber docente é "[...]plural, construído no cotidiano da prática, que lhe dá um caráter de experiência, legitimando-o para tomada de decisões em situação de interação". Sublinha-se nesta perspectiva o caráter relacional e contextual da aquisição dos saberes docentes.

Em relação à formação profissional para a Educação Infantil de modo geral e para o berçário de modo específico, há uma variedade de propostas que podem ser executadas, propiciando às crianças alcançarem seus desenvolvimentos potenciais (VYGOTSKI, 1994) por meio da aprendizagem. Para isso, os/as professores/as precisam amalgamar teoria e prática de modo que a teoria "não seja vista como soberana sobre a experiência da mesma forma que a experiência não substitui a análise crítica, sendo, na verdade, mediada por ela" (KRAMER, 1986, apud BODNAR, 2011, p. 199). 


\section{CRIAR EDUCAÇÃO}

Revista do Programa de Pós-Graduação em Educação - UNESC

\section{(1)}

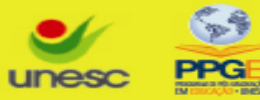

Os/as professores/as precisam refletir sobre a sua prática pedagógica (tendo a teoria como pano de fundo) para que possam redimensioná-la, reconhecendo suas ações como transformadoras da realidade social. Devem perceber que a aprendizagem é individual, mas somente ocorre num ambiente acolhedor e rico em estímulos. Precisam propiciar às crianças espaços de negociação de regras, combinação de papéis, criação de diferentes hipóteses e possibilidades, conversas, discussões, negação de propostas: tudo isso Ihes possibilita agir sobre o mundo. Enfim, os/as professore/as devem atuar como mediadores/as do conhecimento, problematizadores/as, instigadores/as da curiosidade dos bebês e, em conformidade com as Diretrizes Curriculares Nacionais para a Educação Infantil (BRASIL, 2010), suas propostas pedagógicas devem respeitar princípios éticos, políticos e estéticos.

O RCNEI (BRASIL, 1998, p. 41) aponta que o perfil do/a educador/a da Educação Infantil deve ser polivalente, pois ele/a atuará no fornecimento dos cuidados básicos e, também, mediará conhecimentos específicos, provenientes das diferentes áreas do conhecimento.

Este caráter polivalente demanda, por sua vez, uma formação bastante ampla do profissional que deve tornar-se, ele também, um aprendiz, refletindo constantemente sobre sua prática, debatendo com seus pares, dialogando com as famílias e a comunidade e buscando informações necessárias para o trabalho que desenvolve.

Pelo que foi colocado até o momento, percebe-se que investir na formação profissional dos/as educadores/as que atuarão na Educação Infantil fornece a base para a educação das crianças, que se inicia na Educação Infantil e avança aos níveis subsequentes.

\section{A MEDIAÇÃO DA LINGUAGEM NO ESPAÇO DO BERÇÁRIO}

Em relação ao desenvolvimento da linguagem, tema abordado por Lima (2015), a capacidade de comunicação possibilita imprimir sentidos e registrar as impressões humanas. É na linguagem, e por meio dela, que a criança constrói sua leitura do mundo e da sua própria história (VYGOTSKI, 1994).

Segundo a teoria vygotskiana, a primeira etapa do desenvolvimento da linguagem é a pré-linguística, na qual se destacamos ruídos, o choro, os murmúrios, a produção 
de sons vogais e os balbucios (ARCE; MARTINS, 2012). Segundo Rego (2014), estes têm função de alívio emocional e são meios de contato com os membros do grupo social. Para Souza (2012, p. 128), a função social da fala é valorizada na teoria vygotskiana desde os primeiros meses. "A criança [...] comunica suas sensações de prazer e desprazer, que são habilmente decodificadas pela mãe ou adulto significativo do seu meio circundante".

$\mathrm{Na}$ sequência do desenvolvimento da linguagem, no segundo ano de vida, surge o domínio primário do idioma com as primeiras palavras (ARCE; MARTINS, 2012). "Na medida em que a criança interage e dialoga com os membros mais maduros de sua cultura, aprende a usar a linguagem como instrumento do pensamento e como meio de comunicação" (REGO, 2014, p. 65). Segundo a teoria vygotskiana, nesta etapa o pensamento e a linguagem se fundem, o pensamento se torna verbal e a fala racional.

No terceiro ano de vida, inicia-se a etapa do domínio da estrutura gramatical da língua, a criança amplia seu vocabulário e começa a construir frases (ARCE; MARTINS, 2012). Segundo Rego (2014), ela passa a ser capaz de planejar ações futuras, indo além das suas experiências imediatas.

Segundo o RCNEI (BRASIL, 1998), o trabalho com a linguagem se constitui em um dos eixos básicos na Educação Infantil, assim é importante que os/as docentes estimulem diferentes expressões, pois o período de 0 a 3 anos é uma fase de importantes aquisições. Cada movimento que os bebês fazem é uma estratégia de comunicação: eles usam seu corpo, seus gestos e outras formas de expressão para demonstrar o que estão pensando e sentindo e os/as docentes precisam estar atentos/aspara decodificar o que as crianças querem transmitir. As crianças pequenas precisam estar envolvidas em planejar ações e ter um diálogo atrativo com os adultos e não somente ouvir ordens. O/A professor/a precisa compreender e respeitar que cada educando/as e desenvolve em um ritmo que the é próprio. Além disso, cabe ao/à docente mediar a interação das crianças entre si.

Nas entrevistas realizadas por Lima (2015) com as professoras regentes da turma observada, elas narraram ser necessário dar plena atenção às manifestações verbais das crianças, estimulá-las, oferecer-lhes palavras novas e não usar com elas uma fala infantilizada. Nas palavras de uma das entrevistadas: "[...] os alunos, 
apesar de serem pequenininhos, estão prestando atenção, vendo os nossos gestos, o modo como nós falamos" (LIMA, 2015, p. 65). Castro (2011) confirma esta tese, pois a autora afirma que os bebês já são capazes de fazer interpretações, têm sensibilidade para se expressarem em múltiplas linguagens, criatividade e intencionalidade em suas ações. A escola, por apresentar-se como um espaço educativo por excelência, precisa oferecer propostas pedagógicas que propiciem aos bebês elaborarem estratégias de pensamento e de ação. Ao mediarem a linguagem dos bebês, os/as professores/as permitem "[...] que se crie uma situação de ajuda na qual as crianças avancem no seu processo de aprendizagem" (BRASIL, 1998, p. 31).

Nas observações realizadas por Lima (2015) na turma do berçário, a autora apontou como ferramentas utilizadas pelas professoras para mediar o desenvolvimento da linguagem dos bebês a música, as expressões lúdicas, a contação de histórias e as atividades dirigidas, que representavam momentos de interação das professoras com as crianças e delas entre si. A construção da linguagem não é linear e ocorre num processo de aproximações sucessivas com a fala do outro (BRASIL, 1998). Destacou-se aqui um exemplo extraído da autora, no qual a professora criou uma Zona de Desenvolvimento Proximal (VYGOTSKI, 1994) ao nominar o signo social que representava um determinado objeto para que o bebê dele se apropriasse: “'Que desenho é esse?', apontando para o desenho. Antônio diz: 'não seii' e ela fala: 'guarda sol'. Ele repete: 'gada sol'” (LIMAS, 2015, p. 45).

Limas notou, com base em Vygotski (1994), que o pensamento destas crianças começa a se tornar verbal e a linguagem relacional, enunciando suas ações e pensamentos, como neste trecho em que o menino lhe avisa que vai buscar uma boneca para prosseguir sua brincadeira: "Matheus vem em minha direção. Ao meu lado tem um bercinho, ele diz 'neném' e sai. Volta com um bebê, senta, coloca o bebê no berço e diz 'neném'. Começa a mexer o berço como se estivesse embalando um bebê" (LIMAS, 2015, p. 50).

Limas (2015, p. 67) observou que as professoras utilizam com frequência o recurso da contação de histórias para mediar o desenvolvimento da linguagem. Conforme o relato de uma delas: "quando você está fazendo uma contação de história, você está falando novas palavrinhas, mostrando um leque de opções de palavras novas e eles

Criar Educação, Criciúma, v. 6, nº1, julho/novembro 2016.- PPGE - UNESC 


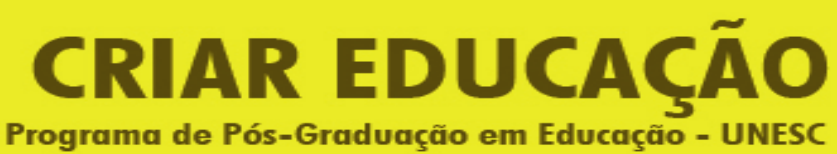

Revista do Programa de Pós-Graduação em Educação - UNESC

西

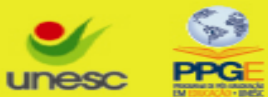

ediunesc

prestam atenção porque eles adoram uma historinha". O ato de contar histórias é uma ação cultural, de interação social, traz grandes contribuições para a aquisição da linguagem, além de contribuir na formação de futuros leitores (BRASIL, 1998).

$\mathrm{Na}$ troca de fraldas, ação de cuidado e higiene, Limas (2015, p. 54) notou uma forte relação afetiva formada entre a professora e um bebê, representada pelo "olho no olho, carinho e atenção", além do diálogo que ela estabeleceu com o menino sobre elementos do espaço da creche: "'Cadê a Genoveva'. Genoveva é a vaquinha que ele adora brincar na creche. Ele diz: 'foi bora'”. A outra professora da turma narrou que costuma cantar uma música para acalmar outro bebê agitado durante a troca da fralda.Estas ações mediam linguagens e afetos, amalgamando cuidar e educar.

Limas (2015, p. 57) observou que a interação entre os pares também é importante fonte de desenvolvimento da linguagem, principalmente por meio da imitação, como pode ser visualizado no trecho a seguir: "Adriano coloca sua mão no rosto e tira. Diz: 'Achouuuu'. João que está sentado na mesinha olha e começa a imitar o colega, fazendo a mesma coisa de pôr e tirar a mão do rosto e falar: 'achouuuuu'”. Segundo o RCNEI, "a imitação é resultado da capacidade de a criança observar e aprender com os outros e de seu desejo de se identificar com eles, de ser aceita e de diferenciar-se" (BRASIL, 1988, p. 21). Conforme Castro (2011) na interação entre os bebês, eles se apropriam do conteúdo que o outro lhes transmite e se constituem enquanto sujeitos de linguagem.

Por fim, Limas (2015, p. 70) perguntou às professoras se elas corrigiam a fala errada das crianças e ambas relataram que quando uma palavra ou frase é pronunciada de forma incorreta, elas se aproximam da criança e a repetem corretamente, sem corrigi-la. Uma das professoras reforçou que não acha "engraçadinho" quando as crianças falam errado e as estimula a falar corretamente. O RCNEI (BRASIL, 1998, p. 136) apoia a postura das professoras: "cabe ao professor, atento e interessando, auxiliar na construção conjunta das falas das crianças para torná-las mais completas e complexas". O documento complementa: "os professores podem funcionar como apoio ao desenvolvimento verbal das crianças, sempre buscando trabalhar com a interlocução e a comunicação efetiva entre os participantes da conversa".

\section{A BRINCADEIRA NO ESPAÇO DO BERÇÁRIO}

Criar Educação, Criciúma, v. 6, ㄲo1, julho/novembro 2016.- PPGE - UNESC 
Quanto à influência da brincadeira no processo de ensino-aprendizagem, tema abordado por Taborda (2015), a formação docente precisa instrumentalizar o/aprofessor/a a incentivar o brincar e a oferecer ambientes ricos em estímulos lúdicos, adequados à faixa etária, pois brincar é uma atividade basilar ao desenvolvimento da identidade e da autonomia (BRASIL, 1998). "As interações e a brincadeira são consideradas eixos fundamentais para se educar com qualidade" (BRASIL, 2012, p. 7). Na brincadeira, a criança assume uma posição de sujeito ativo, opina, produz cultura e desenvolve suas potencialidades sociais, cognitivas, psicológicas e físicas.

O brincar proporciona à criança mexer com o seu corpo e com a sua mente, podendo mostrar o que gostaria de ser e de representar e é uma expressão de sua criatividade. Pelo brincar a criança se desenvolve, constrói conceitos e valores e resolve problemas. É uma atividade natural da criança, sendo a primeira fase de aprendizagem. O brincar também foi classificado como elemento de socialização, pois através dele a criança aprende as regras e os limites, o que a ensina a viver em sociedade. (CARVALHO; ALVES; GOMES, 2005, p. 224)

As primeiras manifestações do brincar em bebês surgem no contato com a figura materna. Para Bondiolie Mantovani (1998),o adulto torna-se um "brinquedo" interessante, pois é capaz de responder de maneira ativa, adaptável e contingente às ações infantis, ou seja, ele assume o papel do brinquedo que a criança tenta dominar e colocar sob o seu controle. Assim, "o bebê começa brincando com os próprios sentidos, num crescente jogo de descobertas, desenvolvimento de habilidades e construções de significados" (ORTIZ; CARVALHO, 2012, p. 103).

Gradativamente as brincadeiras se ampliam e, da atividade sensório-motora, surge a brincadeira simbólica ou faz de conta. Para Vygotski (1994), imaginar é um processo novo para a criança e representa uma forma especificamente humana de atividade consciente, tal qual a linguagem, diferenciando-a dos demais animais. No brinquedo, a criança cria uma situação imaginária na medida em que aprende a agir na esfera cognitiva (interna) ao invés da esfera visual (externa) e passa a obedecer às regras impostas na brincadeira. "A criança imagina-se como mãe e a boneca como criança e, desta forma, deve obedecer às regras do comportamento maternal" (VYGOTSKI, 1994, p. 124). Assim, o jogo simbólico ou faz de conta cria uma Zona de 
Desenvolvimento Proximal. "No brinquedo, a criança sempre se comporta além do comportamento habitual de sua idade, além de seu comportamento diário; no brinquedo é como se ela fosse maior do que é na realidade" (p. 125).

Ao diferenciar jogo, brincadeira, brinquedo e lúdico, Dallabona e Mendes (s/d, p. 3) apontam que brincadeira se refere à ação de brincar, divertimento, geralmente constituída por uma atividade espontânea e não estruturada. Já o jogo envolve regras preestabelecidas, exercidas em certos limites de tempo e espaço. Brinquedo é o suporte da brincadeira, objeto destinado ao divertimento da criança. E atividade lúdica é um conceito mais amplo, que abrange os anteriores.

Taborda (2015) analisou o brincar no espaço da creche enquanto uma atividade sociocultural, na qual as interações se desenvolvem no contato com o meio,com as outras crianças, com os/as professore/as e demais funcionários/as. Por meio do lúdico, as crianças aprendem de maneira prazerosa; expressam suas vontades, sentimentos e fantasias; constroem, reconstroem e transformam o mundo à sua volta, de forma ativa, reproduzindo e produzindo cultura.

Vivemos num mundo onde o lúdico está gradativamente perdendo espaço. O tempo de brincar tem diminuído, seja pela redução do espaço físico das moradias, pela extinção ou sucateamento das praças eplaygrounds, pelo excesso de atividades imputadas às crianças ou pela colonização tecnológica do brincar (DALLABONA; MENDES, s/d).A Educação Infantil é um dos poucos espaços onde o jogo e a brincadeira ainda resistem e se manifestam.

No berçário, o/a professor/aprecisa planejar situações nas quais as brincadeiras,sejam estas livres ou dirigidas,potencializem o desenvolvimento dos bebês. É importante que o/a educador/a incentive a livre expressão das crianças, intervindo de maneira positiva nos conflitos, na maioria das vezes resultantes da disputa de brinquedos (ORTIZ; CARVALHO, 2012). Wasjkop (1995, p. 68) pontua ser importante ao/à educador/a "observar e registrar as brincadeiras espontâneas das crianças, suas falas, os brinquedos que inventam, assim como nossas atitudes, ideias e dificuldades frente a essas situações [...]", objetivando melhor conhecê-las e ao seu meio social, potencializando reflexões e a criação de novas estratégias pedagógicas. 
O RCNEI(BRASIL, 1998) preconiza que a sala do berçário seja organizada dispondo brinquedos adequados à faixa etária, instrumentos musicais, brinquedos que propiciem o faz de conta, fantasias, blocos de encaixe, espelhos e outros materiais que estimulem a ludicidade. $O$ documento acrescenta que a organização da rotina deve contemplar, na mesma medida, cuidados, brincadeiras e atividades orientadas. É importante que os/as professores/as criem espaços para as diferentes manifestações e linguagens do brincar e demonstrem respeito pelas ideias, teorias e hipóteses das crianças, com curiosidade e admiração.

Taborda (2015) organizou os dados coletados em sete categorias, representando os diferentes modos de brincar. As observações da autora denotam que os bebês realizam brincadeiras sensório-motoras, faz de conta, imitação, brincam principalmente de forma isolada, mas fazem algumas brincadeiras interativas, e suas ações se sustentam num curto espaço de tempo. Extraí das observações da autora um exemplo de brincadeira motora, muito apreciada nesta faixa etária: "C5 escolhe algumas peças de lego e expõe as peças em cima da mesa, colocando uma em cima do outra, olhando para os colegas e dizendo 'não, não'” (TABORDA, 2015, p. 32). O lego de tamanho grande e cores vibrantes é um objeto apropriado para esta faixa etária e propicia à criança brincar de construção. As ações de empilhar e construir auxiliam no desenvolvimento infantil e permitem à criança autonomia para criar diversas formas de brincar, explorando sua criatividade (FRIEDMANN, 2012).

Taborda (2015) também aplicou questionários a seis professoras que atuavam em escolas públicas no município de Palhoça. Uma cursava Pedagogia, cinco eram pedagogas formadas e, destas, quatro tinham Pós-Graduação na área de Educação. A experiência profissional das entrevistadas variava entre 2 e 15 anos. As professoras Beatriz e Bianca (nomes fictícios) relataram que a brincadeira possui base afetiva e proporciona à criança expressão corporal a fim de demonstrar suas emoções. Estas significações atribuídas pelas professoras vão ao encontro da literatura: "nenhuma criança brinca só para passar o tempo, sua escolha é motivada por processos íntimos, desejos, problemas e ansiedades" (GARDNEI, apud FERREIRA; MISSE; BONADIO, 2004, p. 222).

Algumas professoras narraram utilizar certas brincadeiras como recursos pedagógicos, demonstrando intencionalidade relacionada ao brincar. A professora 
Andreia relatou uma das propostas pedagógicas executadas: "as crianças rasgaram revistas e papietaram para confeccionar os três porquinhos. Este processo aconteceu com o intuito de trabalhar a história" (TABORDA, 2015, p. 45). Ao realizar esse tipo de atividade pedagógica em grupo, a criança cria, produz, manifesta suas vontades e se apropria da sua cultura (NAVARRO, 2009).

As professoras Ana Paula, Fernanda e Bianca relataram que costumam oferecer às crianças trabalhos pedagógicos com materiais recicláveis. A professora Beatriz detalhou que trabalha com colagens, pinturas, picar papéis, montagens etc. Ana Paula descreveu uma das atividades, na qual as crianças "confeccionaram um tambor com lata de leite e balão e brincaram batendo com a colher de pau, onde o efeito do balão imitia sons" (TABORDA, 2015, p. 45). Bianca narrou a confecção de um "[...] cavalinho de pau. Neste processo de construção, elas [as crianças] ajudaram em várias etapas, desde o inicio" (p. 45).

A professora Andreia mencionou serem comuns as brincadeiras com "bonecas, fazer comidinha, ouvir histórias e a criança recontar, cantar músicas em roda, brincar de roda, jogos com bola, de encaixe, dança etc."(TABORDA, 2015, p. 46). As professoras narraram que costumam incentivar as brincadeiras de faz de conta e de roda ou cirandas. A professora Ana Paula citou ser frequente a adoção de "cantigas de roda e brincar de cadê-achou" (p. 48). Segundo Friedmann (2012), a brincadeira de roda pode ser realizada em grupos pequenos ou grandes, com as crianças sentadas ou em pé. Estas têm grande potencial de interação, pois as crianças compartilham movimentos, ritmos, melodias e a alegria de estarem todas juntas, ampliando repertórios verbais e motores, atuando na sua socialização.

Finalmente, quanto à compra de brinquedos novos pela escola, as professoras relataram que raramente estas são efetuadas. Maria relatou que "no inicio do ano os pais trazem um brinquedo e muitas doações são adquiridas ao longo do ano"(TABORDA, 2015, p. 47). Todas as professoras disseram fazer o descarte de brinquedos velhos e quebrados. Segundo o RCNEI, é necessário que os brinquedos sejam seguros, resistentes, adequados à faixa etária da criança e estejam em bom estado de conservação (BRASIL, 1998).

\section{CONSIDERAÇÕES FINAIS}

Criar Educação, Criciúma, v. 6, no1, julho/novembro 2016.- PPGE - UNESC 
Amalgamando as análises tecidas por Taborda (2015)e Limas (2015), as autoras puderam constatar a superação da dicotomia entre o cuidar e o educar na prática pedagógica do berçário nas turmas nas quais foram realizadas as pesquisas, pois as diversas interações nos espaços da creche se demonstraram plenas em potencialidades de aprendizagens, não estando estas restritas à "hora da atividade". As autoras puderam perceber a participação ativa dos bebês nas brincadeiras, cirandas, contação de histórias, atividades orientadas, jogos e diálogos, fazendo uso de várias linguagens para expressarem suas ideias, emoções e sentimentos, tendo seu desenvolvimento ampliado pela mediação atenta das professoras.

Este artigo também buscou discutir a relevância da formação docente aprofundar conhecimentos quanto ao desenvolvimento físico, cognitivo, afetivo e sócio histórico das crianças. Ora, os processos de formação precisam instrumentalizar o/as professore/as atuantes na Educação Infantil para que estes/as propiciem aprendizagens significativas para os bebês matriculados no berçário. Eles/as precisam conhecer em profundidade como estes sujeitos se desenvolvem e se constituem, desde uma compreensão sócio histórica. Munidos/as desta percepção mais ampla, poderão acolher cada criança em sua singularidade e the mediar novos conhecimentos, dentro dos limites de sua Zona de Desenvolvimento Proximal (VYGOTSKI, 1994). Isso implica observá-los atentamente, respeitá-los, Ihes deixar fazer suas próprias escolhas, Ihes possibilitar a livre movimentação pelos espaços, enfim, Ihes fornecer certa autonomia com segurança.

Consta nos documentos oficiais que o/a professor/a da Educação Infantil precisa ter um perfil polivalente (BRASIL, 1998), pois fornece cuidados básicos e media conhecimentos. Somente processos formativos de qualidade permitirão preparar professores/as reflexivos/as e críticos/as em relação ao ensino e às condições sócio históricas nas quais este se processa, acrescentando qualidade à polivalência profissional.

Libâneo e Pimenta (1999, p. 260) postulam que "a docência constituiu um campo específico de intervenção profissional na prática social - não é qualquer um que pode ser professor". Para os autores, deixa de ser "qualquer um", o/a professor/a que amplia constantemente os conhecimentos sobre sua prática, tanto da sua turma

Criar Educação, Criciúma, v. 6, nº1, julho/novembro 2016.- PPGE - UNESC 


\section{CRIAR EDUCAÇÃO}

Revista do Programa de Pós-Graduação em Educação - UNESC

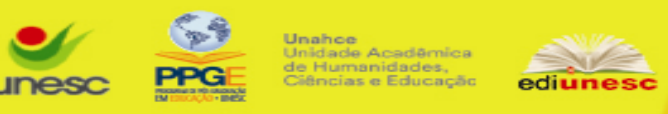

como da escola como um todo, estabelece conhecimentos teóricos e críticos sobre a realidade na qual está inserido/a e compreende o ensino - em todos os níveis como uma prática social, visando transformar continuamente seus saberes-fazeres.

Criar Educação, Criciúma, v. 6, o1, julho/novembro 2016.- PPGE - UNESC 


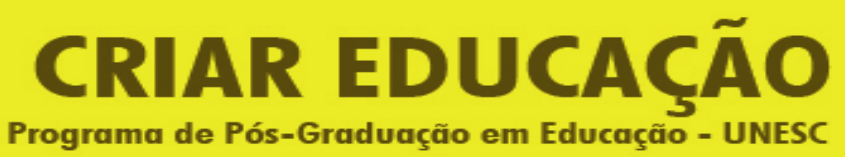

Revista do Programa de Pós-Graduação em Educação - UNESC

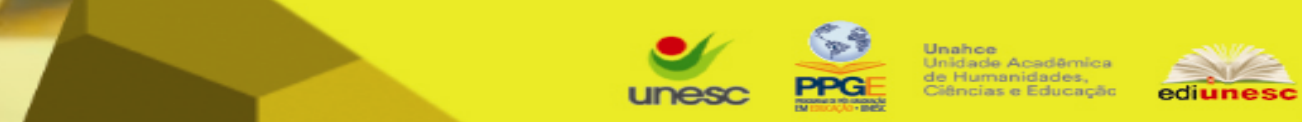

REFERÊNCIAS

ARCE, Alessandra; MARTINS, Ligia Marcia. Ensinando aos pequenos de zero a três anos. 2. ed.Campinas, SP: Alínea, 2012.

BODNAR, Rejane Tereza Marcos. Relação teoria-prática na formação em serviço de profissionais de Educação Infantil: ressignificando a prática pedagógica. In: ROCHA, Eloísa; KRAMER, Sônia (Orgs.). Educação Infantil: enfoques em diálogo. Campinas: Papirus, 2011, p. 195-210.

BONDIOLI, Anna; MANTOVANI, Susanna. Manual de Educação Infantil de zero a três anos: uma abordagem reflexiva. Porto Alegre: Artes Médicas, 1998.

BRASIL. Diretrizes Curriculares Nacionais para a Educação Infantil. Ministério da Educação. Secretaria de Educação Básica. Brasília: MEC, SEB, 1998. Disponível em:http://portal.mec.gov.br/index.php?option=com_docman\&view=download\&alias=9 769-diretrizescurriculares-2012\&category_slug=janeiro-2012-pdf\&Itemid=30192.

Acesso em 15.06.2016.

BRASIL. Brinquedos e brincadeiras de creche: manual de orientação pedagógica. Ministério da Educação. Secretaria de Educação Básica. Brasília: MEC, SEB, 2012.Disponível

em:http://portal.mec.gov.br/dmdocuments/publicacao_brinquedo_e_brincadeiras_co mpleta.pdf. Acesso em 15.06.2016.

BRASIL. Referencial Curricular Nacional para a Educação Infantil. Ministério da Educação. Secretaria de Educação Básica. Brasília: MEC, SEB, 2010.Disponível em:http://portal.mec.gov.br/seb/arquivos/pdf/rcnei_vol1.pdf. Acesso em 15.06.2016.

CARVALHO, Alysson Massote; ALVES, Maria Michelle; GOMES, Priscila de Lara. Brincar e Educação: concepções e possibilidades. Psicologia em Estudo, Maringá/PR, maio/ago., 2005, v. 10, n. 2, p. 217-226. Disponível em:http://www.scielo.br/pdf/pe/v10n2/v10n2a08.pdf. Acesso em 15.06.2015.

CASTRO, Joselma Salazar de. A constituição da linguagem e as estratégias de comunicação dos e entre os bebês no contexto coletivo da Educação Infantil. 2011. 208 f. Dissertação (Mestrado em Educação) - Programa de Pós-Graduação em Educação, Centro de Ciências da Educação. Universidade Federal de Santa Catarina.

Florianópolis, 2011.Disponível em:http://www.pmf.sc.gov.br/arquivos/arquivos/pdf/13_02_2012_11.00.32.65af1867f 93401e552fecbd99e8404ea.pdf. Acesso em 17.08.2015.

Criar Educação, Criciúma, v. 6, no1, julho/novembro 2016.- PPGE - UNESC 
DALLABONA, Sandra Regina; MENDES, Sueli Maria. O lúdico na Educação Infantil: jogar, brincar, uma forma de educar.ICPG - Instituto Catarinense de pósgraduação, s/d. Disponível em: http://www.posuniasselvi.com.br/artigos/rev0416.pdf. Acesso em 20.03.2015.

FERREIRA, Carolina Martins; MISSE, Cristina; BONADIO, Sueli. Brincar na educação infantil é coisa séria. Akrópolis, Umuarama/PR, out./dez., 2004, v. 12, n. 4 ,

222-223.Disponível em:http://revistas.unipar.br/?journal=akropolis\&page=article\&op=view\&path\%5B\%5D $=1959 \&$ path\%5B\%5D=1707. Acesso em: 10.08.2016.

FRIEDMANN, Adriana. O brincar na Educação Infantil: observação, adequação e inclusão. São Paulo: Moderna, 2012.

LIBÂNEO, José Carlos; PIMENTA, Selma Garrido. Formação de profissionais da educação: visão crítica e perspectiva de mudança. Educação \& Sociedade, dez., 1999, ano XX, n. 68, p. 239-277. Disponível em: http://www.scielo.br/pdf/es/v20n68/a13v2068.pdf. Acesso em 20.05.2016.

LIMAS, Nikely Flores. O processo de desenvolvimento da linguagem das crianças de 1 a 3 anos. Trabalho de Conclusão de Curso (Licenciatura em Pedagogia) - Faculdade Municipal de Palhoça. Palhoça /SC, 2015.

NAVARRO, Mariana Stoeterau. O brincar na Educação Infantil.Anais do IXCongresso Nacional de Educação. Paraná: EDUCERE, 2009. Disponível em: http://www.pucpr.br/eventos/educere/educere2009/anais/pdf/2693_1263.pdf. Acesso em 23.05.2010.

OLIVEIRA, Marta Kohl. Vygotsky: Aprendizado e Desenvolvimento, um processo sócio-histórico. São Paulo: Scipione, 1993.

ORTIZ, Gisele; CARVALHO, Maria Teresa Venceslau de. Interações: ser professor de bebês. Cuidar, educar e brincar, uma única ação. São Paulo: Blucher, 2012.

REGO, Teresa Cristina. Vygotsky:uma perspectiva Histórico Cultural de Educação. 25. ed. Petrópolis, RJ: Vozes, 2014.

SOUZA, Solange Jobim e. Infância e linguagem: Bakhtin, Vygotsky, Benjamin. 13 ed. rev. e ampl. Campinas, SP: Papirus, 2012.

Criar Educação, Criciúma, v. 6, nº1, julho/novembro 2016.- PPGE - UNESC 
TABORDA, Adriele de Souza. O brincar na infância. Trabalho de Conclusão de Curso (Licenciatura em Pedagogia) - Faculdade Municipal de Palhoça. Palhoça /SC, 2015.

THERRIEN, Jacques. Trabalho e saber: a interação no contexto da pósmodernidade. In: MARKERT, Werner (Org.). Trabalho, qualificação e politecnia. Campinas: Papirus, 1998, p. 53-70.

VYGOTSKY, L. S. Aformação social da mente: o desenvolvimento dos processos psicológicos superiores. Trad. José Cipolla Neto. São Paulo: Martins Fontes, 1994.

WAJSKOP, Gisela. O brincar na Educação Infantil. Cadernos de Pesquisa, São Paulo, fev., 1995, n. 92, p. 62-69. Disponível em: http://www.fcc.org.br/pesquisa/publicacoes/cp/arquivos/742.pdf. Acesso em 23.03.2013. 